\title{
Crosstalk Compensation for a Rapid, Higher- Resolution Impedance Spectrum Measurement
}

\section{Aerospace Conference}

The INL is a

U.S. Department of Energy

National Laboratory

operated by

Battelle Energy Alliance

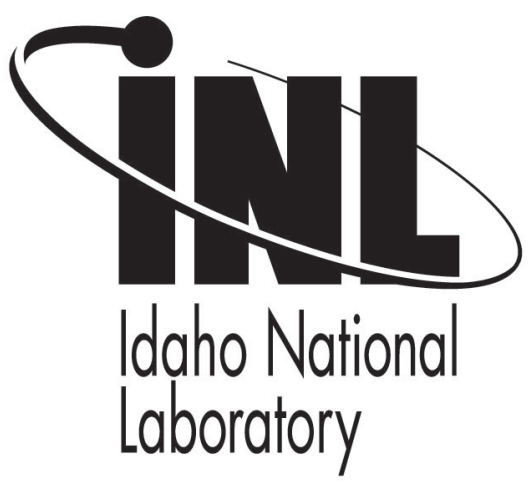

\author{
Jon P. Christophersen \\ John L. Morrison \\ David M. Rose \\ William H. Morrison \\ Chester G. Motloch
}

March 2012

This is a preprint of a paper intended for publication in a journal or proceedings. Since changes may be made before publication, this preprint should not be cited or reproduced without permission of the author. This document was prepared as an account of work sponsored by an agency of the United States Government. Neither the United States Government nor any agency thereof, or any of their employees, makes any warranty, expressed or implied, or assumes any legal liability or responsibility for any third party's use, or the results of such use, of any information, apparatus, product or process disclosed in this report, or represents that its use by such third party would not infringe privately owned rights. The views expressed in this paper are not necessarily those of the United States Government or the sponsoring agency. 


\section{Crosstalk Compensation for a Rapid, Higher-Resolution Impedance Spectrum Measurement}

\author{
Jon P. Christophersen* \\ Idaho National Laboratory \\ P.O. Box 1625 \\ Idaho Falls, ID 83415-2209 U.S.A. \\ 208-526-4280 \\ Jon.Christophersen@inl.gov \\ *corresponding author \\ William H. Morrison \\ Qualtech Systems, Inc. \\ 100 Great Meadow Rd., Suite 603 \\ Wethersfield, CT 06109 U.S.A. \\ 860-805-1828 \\ bill@teamqsi.com
}

\author{
John L. Morrison \\ Montana Tech \\ University of Montana \\ 1300 W. Park \\ Butte, MT 59701 U.S.A. \\ 406-496-4515 \\ jmorrison@mtech.edu \\ Chester G. Motloch \\ Motloch Consulting Inc. \\ 725 W. Riverview Dr. \\ Idaho Falls, ID 83401 U.S.A. \\ 208-529-9963 \\ cmotloch@gmail.com
}

\author{
David M. Rose \\ Montana Tech \\ University of Montana \\ 1300 W. Park \\ Butte, MT 59701 U.S.A. \\ 206-406-5314 \\ fievel.rook@gmail.com
}

\begin{abstract}
Crosstalk Compensation is an approach that enables rapid, higher-resolution impedance spectra measurements of energy storage devices. The input signal consists of a sum-ofsines excitation current that has a known frequency spread. The advantage of Crosstalk Compensation is that high resolution spectra can be acquired within one period of the lowest frequency while also including non-harmonic frequencies. The crosstalk interference at a given frequency can be pre-determined and assigned to an error matrix. The real and imaginary impedance can then be calculated based on the inverse of the error matrix and captured response. Analytical validation of Crosstalk Compensation was performed using a battery equivalent circuit model. Two different frequency ranges were simulated, and both indicated that a minimum step factor between frequencies should be $\mathbf{1 . 2 5}$ to reduce the error in compensating the captured response signal. For a frequency range of 1638.4-0.1 Hz, for example, a maximum of 45 frequencies should be included within the excitation signal to accurately acquire the impedance spectra at high resolution. A simplified derivation of Crosstalk Compensation and its corresponding analytical validation studies are discussed.
\end{abstract}

\section{TABLE OF CONTENTS}

1. INTRODUCTION .1

2. CROSSTAlK COMPENSATION .........................................2

3. ANALYTICAL VALIDATION ............................................4

4. RESULTS AND DISCUSSION .......................................5

5. SUMMARY AND CONCLUSIONS ....................................14

6. NOMENCLATURE..............................................................14

7. ACKNOWLEDGEMENTS ..........................................14

REFERENCES ....................................................................14

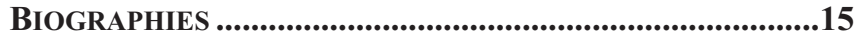

\section{INTRODUCTION}

Energy storage devices are becoming more pervasive in various industries (e.g., military, automotive, electric utilities, etc.) as the U.S. seeks to reduce its dependence on foreign energy resources. Due to the high cost of energy storage devices, including batteries, ultracapacitors, and fuel cells, there is also a growing need for highly accurate and robust state-of-health $(\mathrm{SOH})$ assessment techniques. Existing health assessment methods tend to focus on passive measurements, where the voltage and current are monitored as functions of time and ambient temperature [1-4]. This approach is very beneficial for tracking changes in parameters such as capacity, energy, and state-of-charge (SOC). However, increased performance demands on batteries and other energy storage devices have made simple, passive monitoring an insufficient measure of health and remaining useful life.

Other critical parameters for battery $\mathrm{SOH}$ assessment include resistance growth and available-power fade as functions of time and temperature. A direct approach for gauging changes in resistance and power capability is to conduct constant current pulse tests over a pre-determined SOC range and capture the voltage response [5-8], but this method is not practical for rapid, onboard diagnostics applications. Another approach for indirectly assessing changes in resistance and power has been to use alternating current (AC) impedance spectroscopy measurements over a broad frequency range [9-16]. Impedance spectra measurements consist of exciting the battery with a lowlevel sinusoidal signal with incremental steps in frequency and measuring the response. The excitation signal can either be a voltage or current sine wave. The observed changes in the overall impedance spectra during aging has been shown to linearly correlate with resistance rise and power fade that have been calculated from pulse tests [9-10].

Impedance spectra measurements typically require expensive equipment in a laboratory environment. The measurements are also usually taken sequentially as the frequency is incrementally changed, and this results in long test durations (somewhere in the range of ten minutes to an hour depending on the system settings and frequency range). However, new techniques, known as Compensated Synchronous Detection (CSD) and Fast Summation Transformation (FST) [17-20], have recently been 
developed to enable rapid impedance spectra measurements using a hardware platform that could be designed as an embedded system. Instead of sequentially measuring the impedance at each frequency of interest, the CSD and FST techniques use an excitation signal that consists of a sum-ofsines that simultaneously contains all frequencies of interest.

For CSD [17-18], the sum-of-sines excitation signal usually contains a frequency spread that is logarithmically separated. Since this input signal has a finite duration, it becomes a sequence of sinc functions in the frequency domain, and this can cause crosstalk error in the response. To reduce this error, the input sum-of-sines signal is usually limited to a relatively small number of frequencies or the number of periods of the lowest frequency is increased. It has been shown that 13 frequencies of interest within the excitation signal require a minimum of three periods of the lowest frequency to obtain good results [17]. The battery is excited with this sum-of-sines signal, and the response is captured at a sufficiently fast sampling rate to avoid aliasing errors. The response signal is then demodulated using synchronous detection at each frequency of interest. To compensate for the crosstalk interference, the detected response signal is then reassembled into a sum-of-sines with each frequency except the one of interest. This assembled signal is subtracted from the original response and synchronously detected again at the frequency of interest with a significantly reduced error. A simplified variation of CSD (harmonic CSD) has also been implemented, whereby the excitation signal has a logarithmic frequency spread that is constrained to be harmonic with octaves or triads. The synchronously detected results in this case are not corrupted with crosstalk, and only one period of the lowest frequency is required.

For FST [19-20], the sum-of-sines excitation signal is limited to a frequency spread that is separated by octave harmonics. With octave harmonics, the crosstalk error is eliminated since all of the other sinc functions cross zero at the frequency being detected. Therefore, only one period of the lowest frequency is required to complete a measurement. Additionally, the data processing of the captured time record is significantly less intensive than synchronous detection for harmonic CSD. The battery is excited with this sum-of-sines signal, and the response is captured using a data acquisition system having a sample frequency that is octave and harmonically related to all of the frequencies within the excitation signal. Instead of synchronous detection, as used with CSD, the response signal in this case is rectified relative to the sine and cosine at each frequency of interest. All the samples are then added and normalized by the total number of periods at the given frequency (e.g., only one period for the lowest frequency, two periods for the next lowest frequency, etc.). The real and complex impedances are then computed using a simple matrix calculation consisting of the individually summed samples and the total numerical value determined from the rectified signals [19].
Both the FST and CSD techniques provide results that are directly comparable with standard AC impedance measurements, but they make use of hardware that could be designed as an on-board, embedded system. The FST technique has the advantage of speed (only one period of the lowest frequency required) but at the expense of resolution in the spectra. The CSD technique has the advantage of providing higher-resolution impedance spectra, but at the expense of measurement duration. The purpose of this paper is to describe an alternative impedance measurement technique, known as Crosstalk Compensation (CTC), which enables high-resolution spectra to be acquired within only one period of the lowest frequency.

\section{Crosstalk Compensation}

For CTC, the sum-of-sines excitation signal includes multiple frequencies that can be separated in various ways (e.g., logarithmically, linearly, etc.) without the limitation of harmonic distribution. Since the frequencies of interest in the input signal are known, the existing crosstalk error that will occur from a non-harmonic frequency distribution can be pre-determined and assigned to an error matrix. The response signal can then be compensated with the inverse of the error matrix to identify impedance spectra with high resolution.

The derivation of the CTC technique is based on the input sum-of-sines signal shown in Equation (1), where $A_{i}, T_{i}$, and $\phi i n_{i}$ are the known amplitude, period, and phase of the $i^{\text {th }}$ excitation signal, respectively. Note that the number of frequencies within the excitation signal, $M$, for the CTC can be much larger than CSD or FST since the spread is not limited to harmonics. For example, if a logarithmic distribution is desired for a high-resolution measurement, the step size, $S$, between each frequency within the input signal can be governed by Equation (2). The maximum and minimum frequency ( $f_{\max }$ and $f_{\min }$, respectively) are assumed to be known. Thus, the next frequency on the sequence $\left(f_{i+1}\right)$ is the present frequency $\left(f_{i}\right)$ multiplied by the step factor, as shown in Equation (3).

$$
\begin{gathered}
x(t)=\sum_{i=1}^{M} A_{i} \sin \left(\frac{2 \pi}{T_{i}} t+\phi i n_{i}\right) \\
S=\left(\frac{f_{\max }}{f_{\min }}\right)^{(1 / M-1)} \\
f_{i+1}=S f_{i} \quad i=1: M
\end{gathered}
$$


The battery (or other energy storage device) is excited with the input signal in Equation (1), and the response is captured, as shown in Equation (4), where $B_{i}$ and $\phi_{i}$ are the unknown amplitude and phase of the $i^{\text {th }}$ response signal, respectively. The variable $n$ represents the discrete time step integer $(n=0,1,2,3, \ldots N)$, where $N+1$ is the total number of samples within the captured time record, and $\Delta t$ is the sample time step. This response signal is then synchronously detected with respect to both the sine and cosine of the frequency of interest to find the quadrature and in-phase components of the impedance. Note, however, that for non-harmonic conditions, there will be crosstalk interference error in the results.

$$
y(t)=\sum_{i=1}^{M} B_{i} \sin \left(\frac{2 \pi}{T_{i}} n \Delta t+\phi_{i}\right)
$$

The response signal in Equation (4) can be described by a crosstalk error matrix, $C$, multiplied by an array consisting of the true (but unknown) in-phase and quadrature responses of the battery at each frequency of interest, as shown in Equation (5). The crosstalk error at each detected frequency of interest is primarily caused by the interference of the other frequencies within the excitation signal. In a harmonic spread, these other frequencies converge to zero and the error matrix becomes the identity matrix. The crosstalk compensation matrix can be obtained by taking the Fourier Transform of the right side of Equation (4) and performing the synchronous detection operation for each frequency within the sum-of-sines signal in the frequency domain. The synchronous detection results from the time domain, left side of Equation (4), are then equated to those in the frequency domain, as applied to the right side of Equation(4), yielding a system of equations where the uncorrupted response can be obtained. The synchronous detection of the response signal (or measured time record), $Y$, is a column vector of length $2 M$. The error matrix has a size of $2 M$ by $2 M$, where $M$ is the number of frequencies in the excitation signal. The $[P ; Q]$ array is a column vector of length $2 M$ where the in-phase and quadrature components ( $P$ and $Q$, respectively) are described by Equations (6) and (7), respectively, for the $i^{\text {th }}$ frequency. The expanded form of Equation (5) is shown in Equation (8) when derived in the frequency domain. The error matrix comprises the inphase and quadrature components of the crosstalk effect at each frequency of interest in the response signal. The response of the battery to a given excitation signal, therefore, consists of the inverse of the error matrix multiplied by the synchronously detected measured time record as shown in Equation (9).

The CTC technique enables the rapid acquisition of very high resolution spectra. Depending on the number of frequencies in the excitation signal, however, solving for the error matrix and finding its inverse can become very computationally intensive. But, since the properties of the excitation signal are selected before any measurements are taken, the error matrix can be pre-calculated, and this reduces the required computation time during the actual measurement if speed is required (e.g., for onboard diagnostic applications).

$$
\begin{gathered}
{[Y]=[C]\left[\begin{array}{l}
P \\
Q
\end{array}\right]} \\
p_{i}=B_{i} \cos \phi_{i} \\
q_{i}=B_{i} \sin \phi_{i}
\end{gathered}
$$




$$
\left[\begin{array}{l}
P \\
Q
\end{array}\right]=[C]^{-1}[Y]
$$

\section{AnAlytical Validation}

Validation of the CTC technique was based on a simplified battery model using the equivalent circuit model shown in Figure 1. A test cell circuit (TCC) was built based on this model to verify the consistency of AC impedance measurements between different national laboratories as part of the Applied Battery Research Program [10]. The
TCC equivalent circuit model includes an ohmic resistance $\left(R_{1}\right)$ that is connected to a polarization resistance $\left(R_{2}\right)$ in parallel with a polarization capacitance $\left(C_{l}\right)$. A resistor $\left(R_{3}\right)$ is coupled with the capacitor to capture any resistive elements within the capacitor, including electrical leads, current collectors, and contacts. The ohmic resistance shifts the impedance spectra curve on the real axis and the polarization RC-network produces a semicircle loop that represents a charge transfer resistance [21].

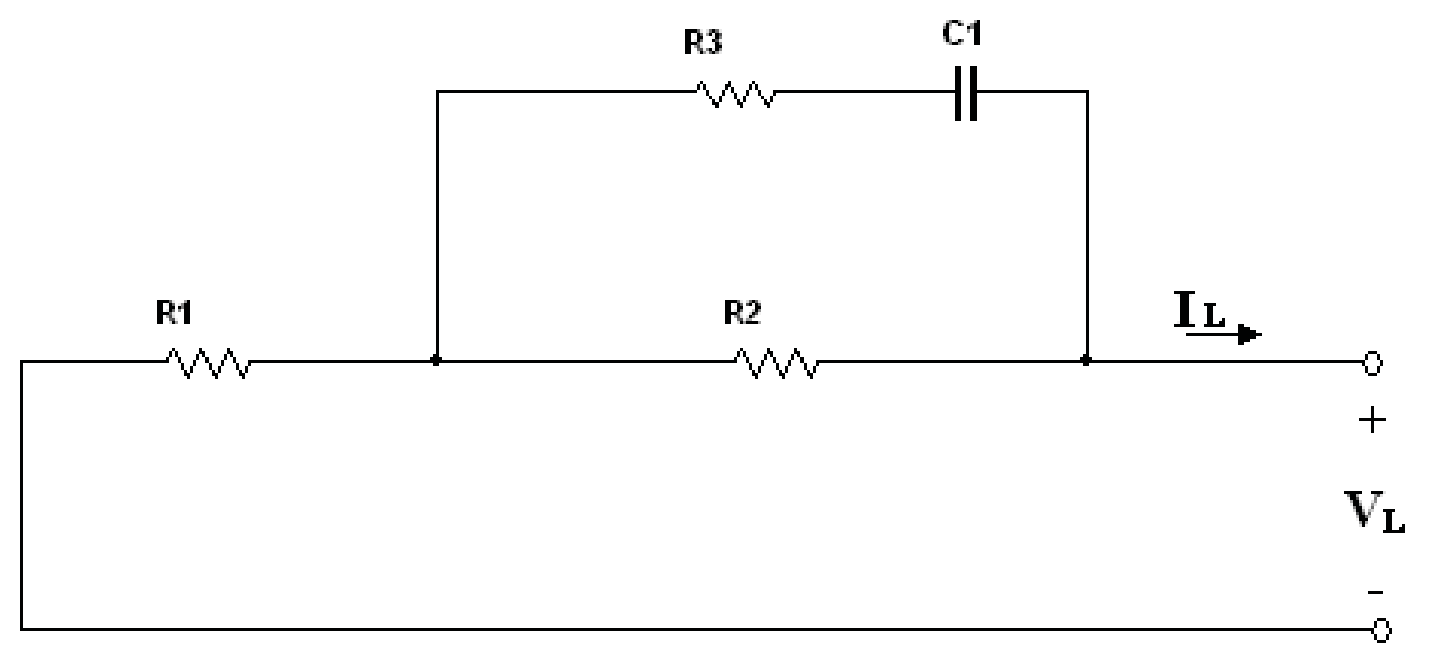

Figure 1. Test cell circuit.

The simulations discussed herein are based on a TCC model having an ohmic resistance $\left(R_{l}\right)$ of $10 \mathrm{~m} \Omega$, polarization resistances $\left(R_{2}\right.$ and $\left.R_{3}\right)$ of $5 \mathrm{~m} \Omega$ each, and a capacitance of $21 \mathrm{~F}$. These parameter values correspond to the TCC that was actually built for the Applied Battery Research Program [10]. The calculated equivalent impedance of the TCC is shown in Equation (10), where $s=j \omega$ contains the frequency component of the impedance. The resulting calculated impedance spectrum of the TCC at various frequencies between 25.6 and $0.025 \mathrm{~Hz}$ (inclusive) is shown in Figure 2. The semicircle loop begins at $12.5 \mathrm{~m} \Omega$ since the capacitor behaves as a short circuit at very high frequencies.
This results in an ohmic resistance of $R_{l}(10 \mathrm{~m} \Omega)$ added to the parallel combination of $R_{2}$ and $R_{3}(5 \mathrm{~m} \Omega$ each). The semicircle loop ends at $15 \mathrm{~m} \Omega$ since the capacitor behaves as an open circuit at very low frequencies, which eliminates $R_{3}$ and results in a series combination of $R_{1}$ and $R_{2}$. Thus, the charge transfer resistance for this TCC model is $2.5 \mathrm{~m} \Omega$ (i.e., the total width of the semicircle).

$$
Z=R_{1}+\frac{R_{2}+s C_{1} R_{2} R_{3}}{1+s C_{1}\left(R_{2}+R_{3}\right)}
$$




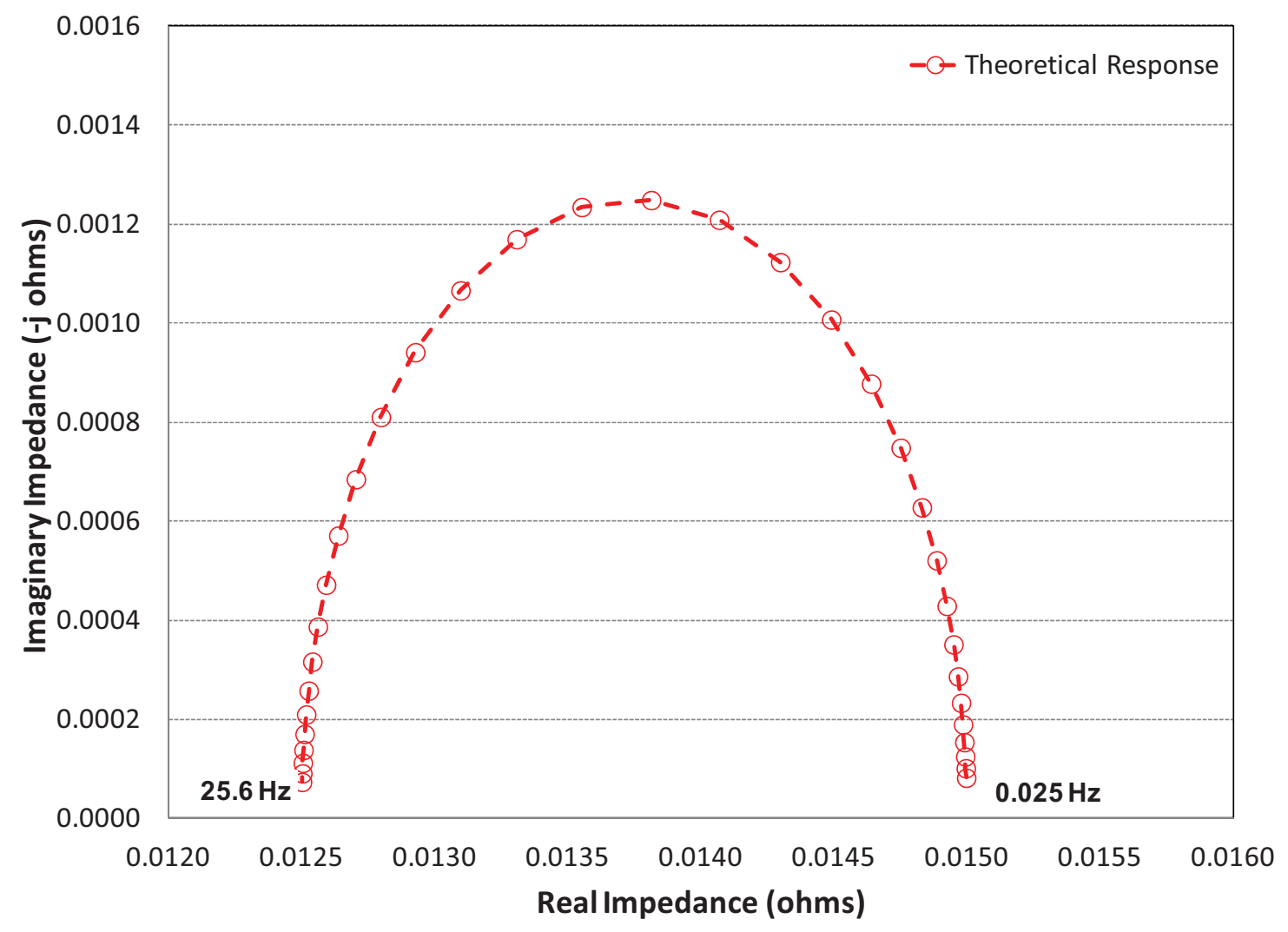

Figure 2. Theoretical Nyquist impedance spectrum for the test cell circuit between 25.6 and $0.025 \mathrm{~Hz}$.

\section{RESUltS AND DiscuSSION}

Impedance spectra based on the CTC technique using the TCC equivalent model were simulated by applying a sumof-sines signal as the load current $\left(I_{L}\right)$ and recursively solving for the load voltage $\left(V_{L}\right)$ response. The simulated load voltage response was then compensated using the pre-determined error matrix to find the in-phase and quadrature components of the impedance. To mitigate the transient effects caused by the size of the capacitor in the TCC, the simulations discussed herein consisted of exciting the equivalent circuit model with a load current having two periods of the lowest frequency. The first period was an initial start-up signal that was a mirror image of the desired excitation signal (this was required as the frequencies were non-harmonic) to eliminate transients, followed by the actual excitation load current signal. The first half of the excitation signal (i.e., the mirror image) was discarded, and the simulated impedance results were based only on the second period of the lowest frequency. Electrochemical transient effects have also been observed in actual cell testing, but previous studies [20] have demonstrated that the transient effects primarily influence the Warburg tail at lower frequencies, though they have minimal impact on the charge transfer resistance region of the spectra. Consequently, only one period of the lowest frequency should be needed to complete a CTC measurement of an actual cell.
The first set of simulations was based on a frequency range of $25.6-0.025 \mathrm{~Hz}$ since this adequately described the charge transfer resistance semicircle, see Figure 2, and the high and low frequencies are harmonically related to each other (i.e., $0.025 \mathrm{~Hz} * 2^{10}=25.6 \mathrm{~Hz}$ ). Given a low frequency of 0.025 $\mathrm{Hz}$, the excitation signal was 40 seconds long; as mentioned above, this signal was preceded by a 40 -second start-up signal to eliminate any transient effects caused by the model parameters. Figure 3 shows the Nyquist curve for both the theoretical impedance (open circles) and simulated CTC response (solid triangles) for one period of the lowest frequency using the harmonic logarithmic spread, where the number of frequencies, $M$, is 11 . Because of the harmonic separation, there is no crosstalk interference and the error matrix, $C$, is a 22 by 22 identity matrix when assembled in the frequency domain. Figure 4 shows the corresponding (a) magnitude and (b) phase plots for both the theoretical and simulated results. As expected, the magnitude of the impedance decreases from $15.0 \mathrm{~m} \Omega$ to $12.5 \mathrm{~m} \Omega$ as the frequency increases from $0.025 \mathrm{~Hz}$ to $25.6 \mathrm{~Hz}$. The corresponding phase response shows a local minimum at the semicircle peak (i.e., in the Nyquist curve of Figure 3) and approaches zero at the high and low frequency extremes, where the impedance is mostly resistive. The impedance data shown in these figures demonstrate that harmonic separation between frequencies yields low-resolution results that are insufficient to fully describe the semicircle arc. The semicircle peak, for example, appears to be more triangular in form due to the sparse dataset. 


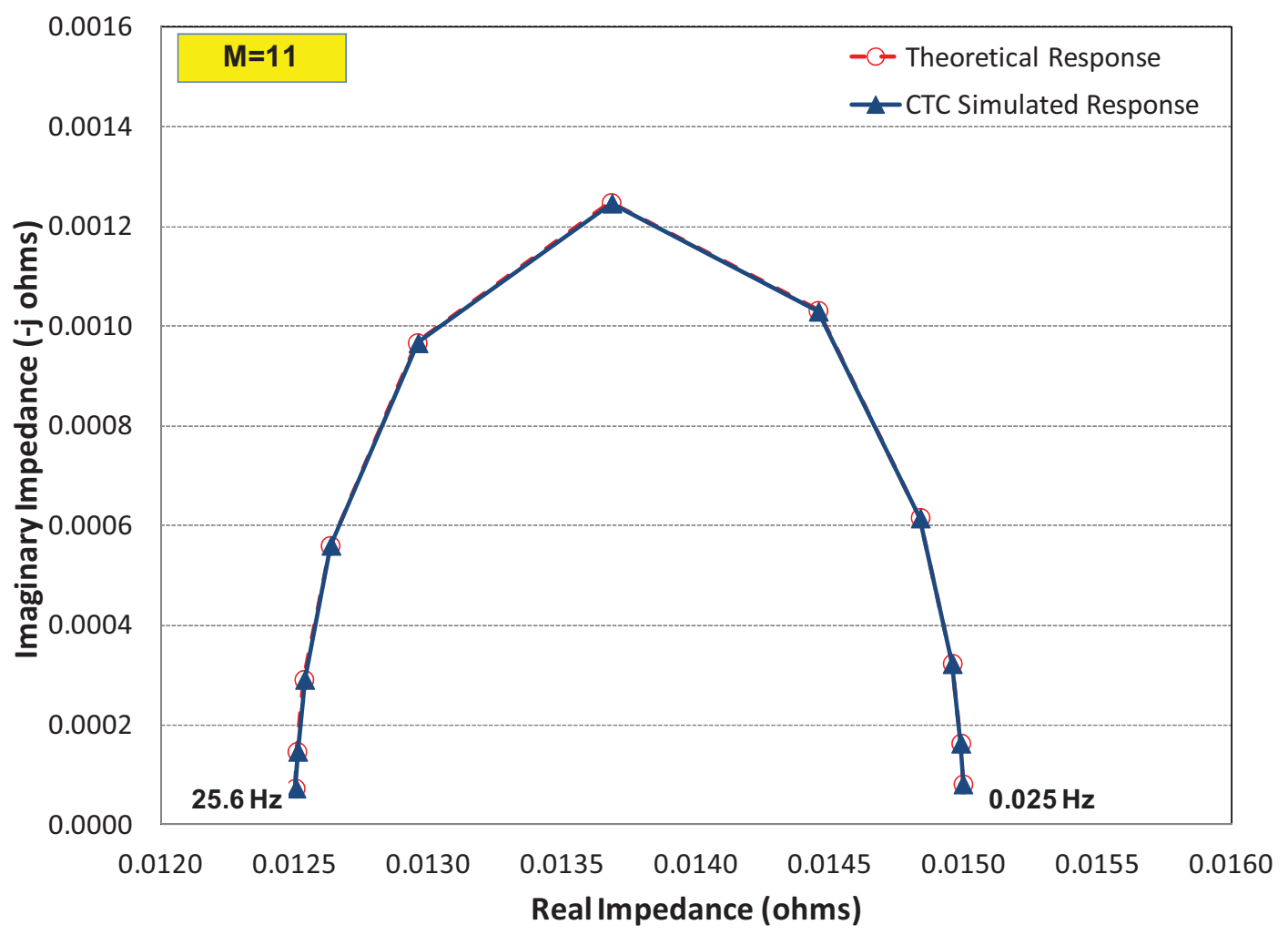

Figure 3. Nyquist curve between 25.6 and $0.025 \mathrm{~Hz}$ using a harmonic frequency spread.

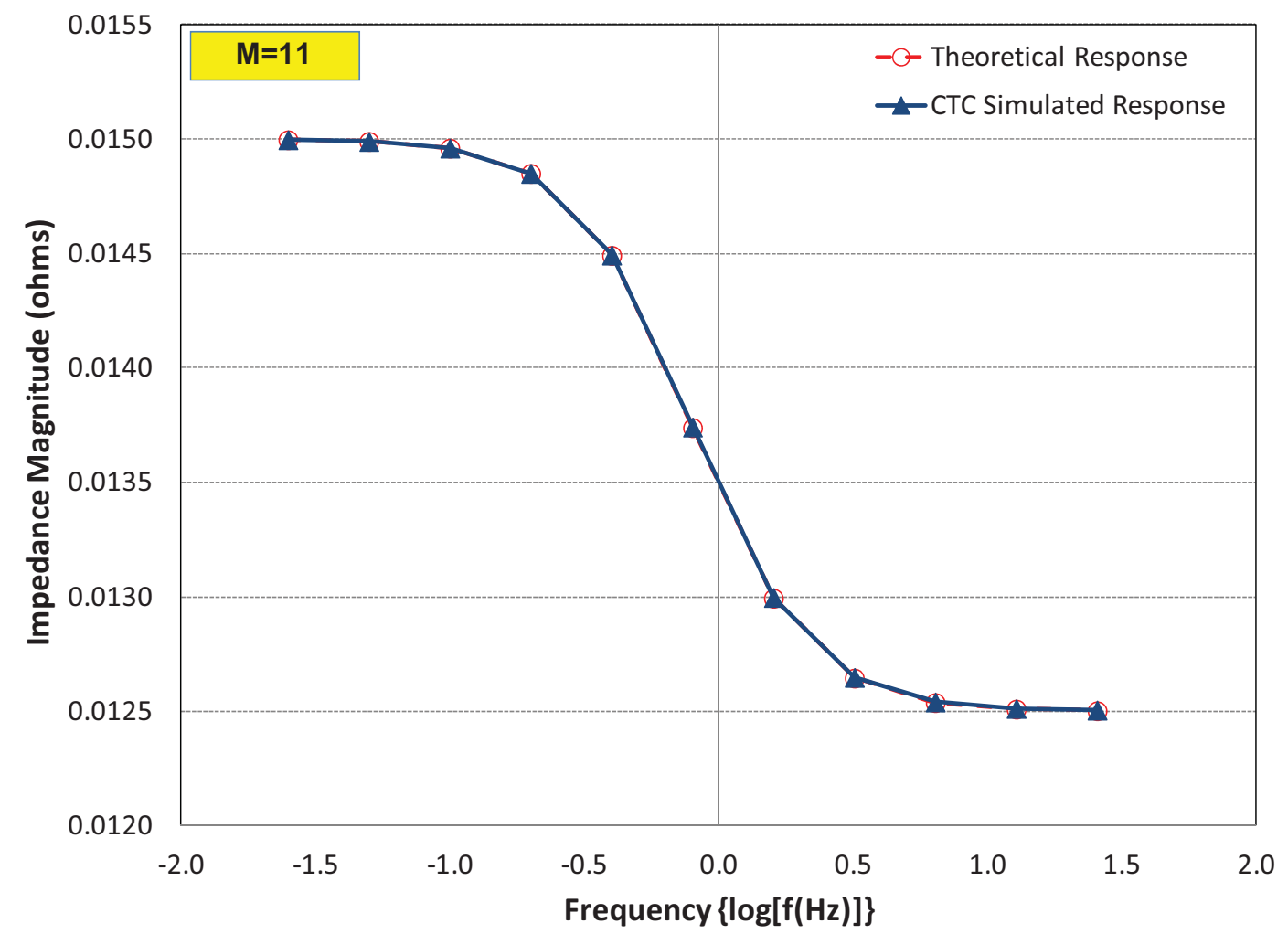

Figure 4a. Magnitude response between 25.6 and $0.025 \mathrm{~Hz}$ using a harmonic frequency spread. 


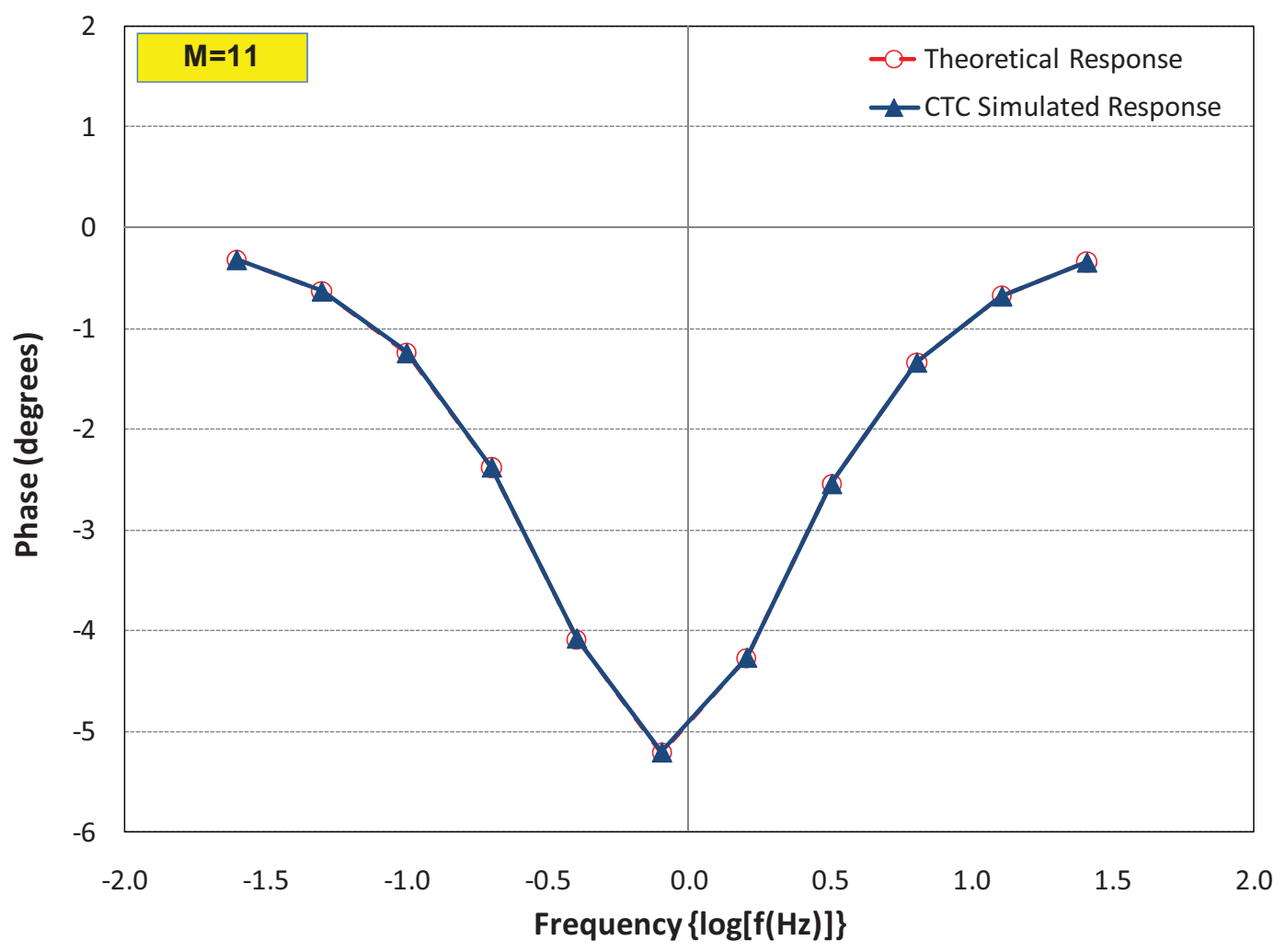

Figure 4b. Phase response between 25.6 and $0.025 \mathrm{~Hz}$ using a harmonic frequency spread.

With CTC, additional frequencies can be added within the sum-of-sines signal to improve the resolution of the semicircle arc without increasing measurement time. Figures 5 and 6 show the Nyquist and Bode plots, respectively, using 32 frequencies between 25.6 and $0.025 \mathrm{~Hz}$, where the step factor, $S$, from Equation (2) is 1.25 (i.e., the frequencies within the excitation signal are 0.025 , $0.031,0.039, \ldots, 20.47,25.6)$. With the increased resolution, the semicircle arc is much better defined, and the theoretical and simulated results still match up very well. To demonstrate the effect of crosstalk interference in the excitation signal, the uncompensated response from the simulation (i.e., $Y$ in Equation [9]) is also shown in these figures with solid squares. The crosstalk effect is obviously worse at lower frequencies where fewer periods at the frequencies of interest are included within the overall load current. As the frequency of interest gets larger, more periods are included within the sum-of-sines signal and this enables a better averaging of the detected impedance and a reduced impact from the crosstalk interference. Thus, the uncompensated results tend to converge towards the theoretical response at larger frequencies.

Figure 7 shows the error between the theoretical and simulated results (with compensation) for the 32 frequencies included in the load current based on the expression shown in Equation (11). The maximum error in the real impedance is below $34 \mu \Omega(0.026 \%$ of the corresponding theoretical real impedance) and the imaginary component is below $2 \mu \Omega$ at its peak $(0.175 \%$ of the corresponding theoretical imaginary impedance). Increasing the number of frequencies in the excitation signal above 32, however, introduces much larger errors in the simulated results for this particular frequency range. Table 1 shows the maximum error calculated from Equation (11) in the magnitude, phase, real, and imaginary components of the impedance for increasing frequencies. Beyond 32 frequencies, the maximum error in the simulated results generally increases by a factor of five or more with each additional frequency added to the excitation signal. These data indicate that the minimum step factor between frequencies should be 1.25 given the TCC model. Figure 8 shows the compensated Nyquist curve when 34 frequencies are included in the sumof-sines excitation signal. The error in the simulated response is clearly evident in the lower-frequency region when the step factor is made too small.

$$
E=\max (\mid C T C-\text { Theoretical } \mid)
$$

Although a frequency range of 25.6 to $0.025 \mathrm{~Hz}$ adequately describes the semicircle of the TCC model, a 40-second excitation signal is not very practical for rapid, onboard applications. For typical lithium-ion cell chemistries, a more common frequency range is between 1638.4 and $0.1 \mathrm{~Hz}$ [20]. This results in only a 10 -second measurement for one period of the lowest frequency. 


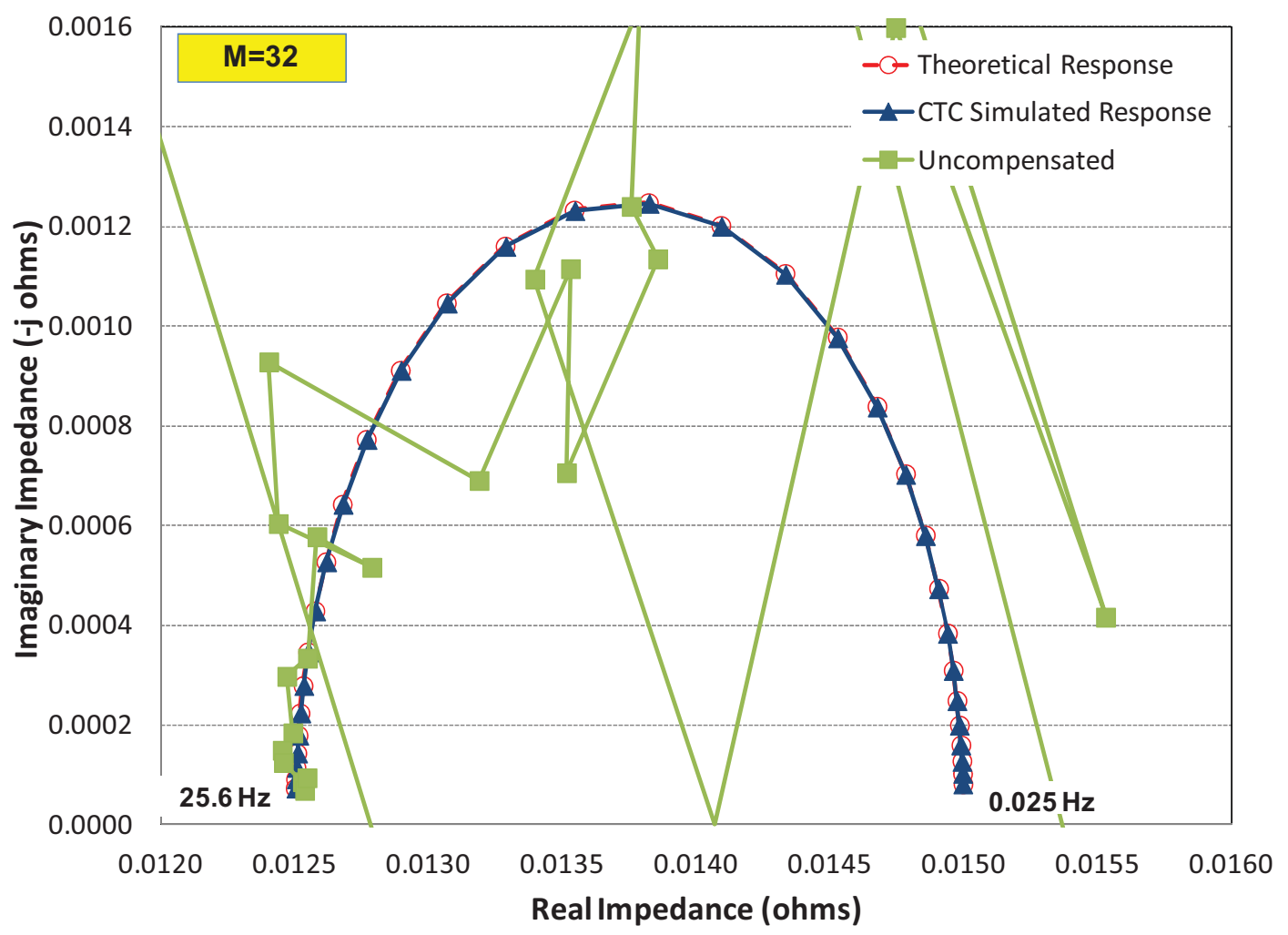

Figure 5. Nyquist curve between 25.6 and $0.025 \mathrm{~Hz}$ with 32 frequencies.

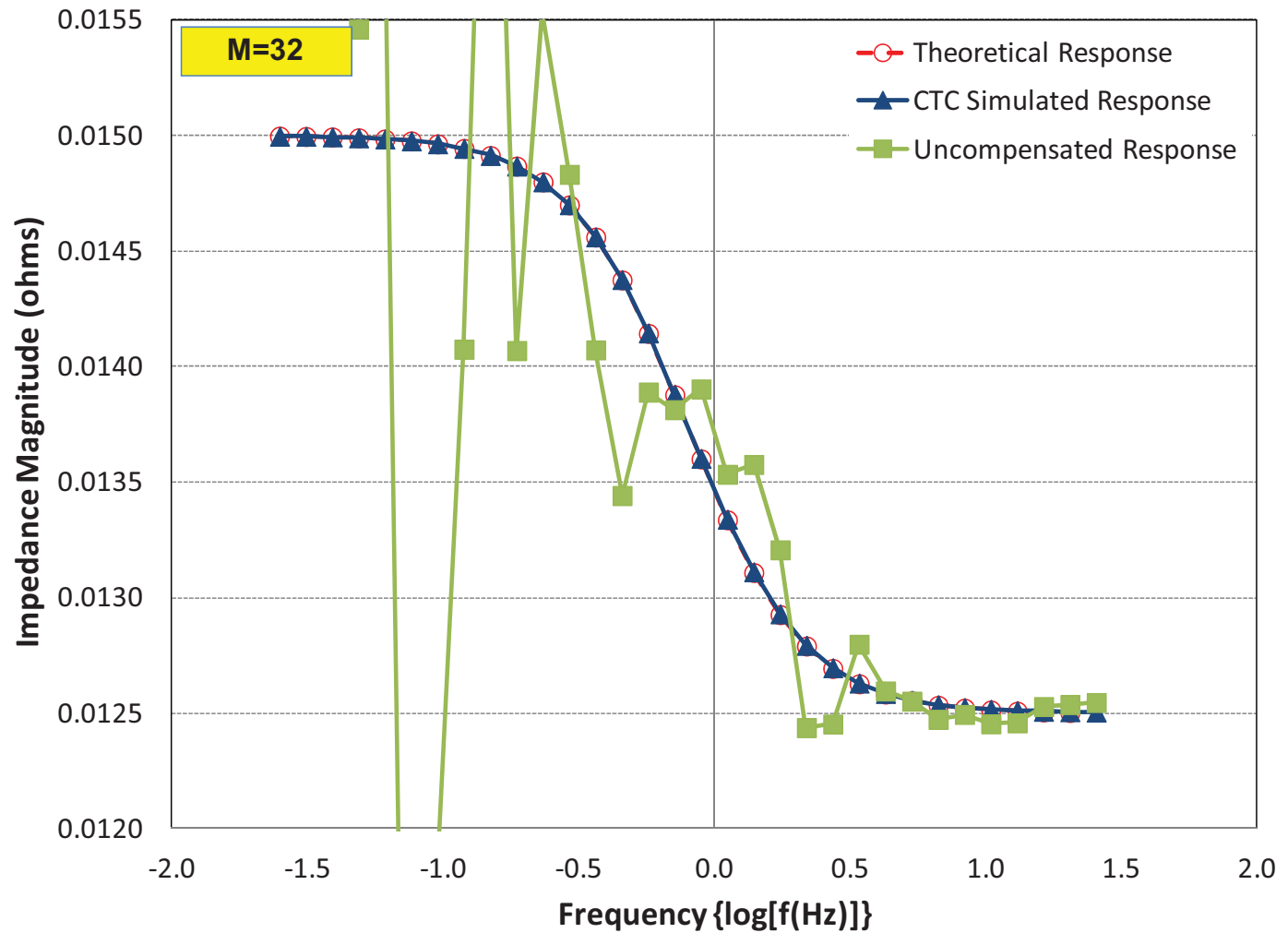

Figure 6a. Magnitude response between 25.6 and $0.025 \mathrm{~Hz}$ with 32 frequencies. 


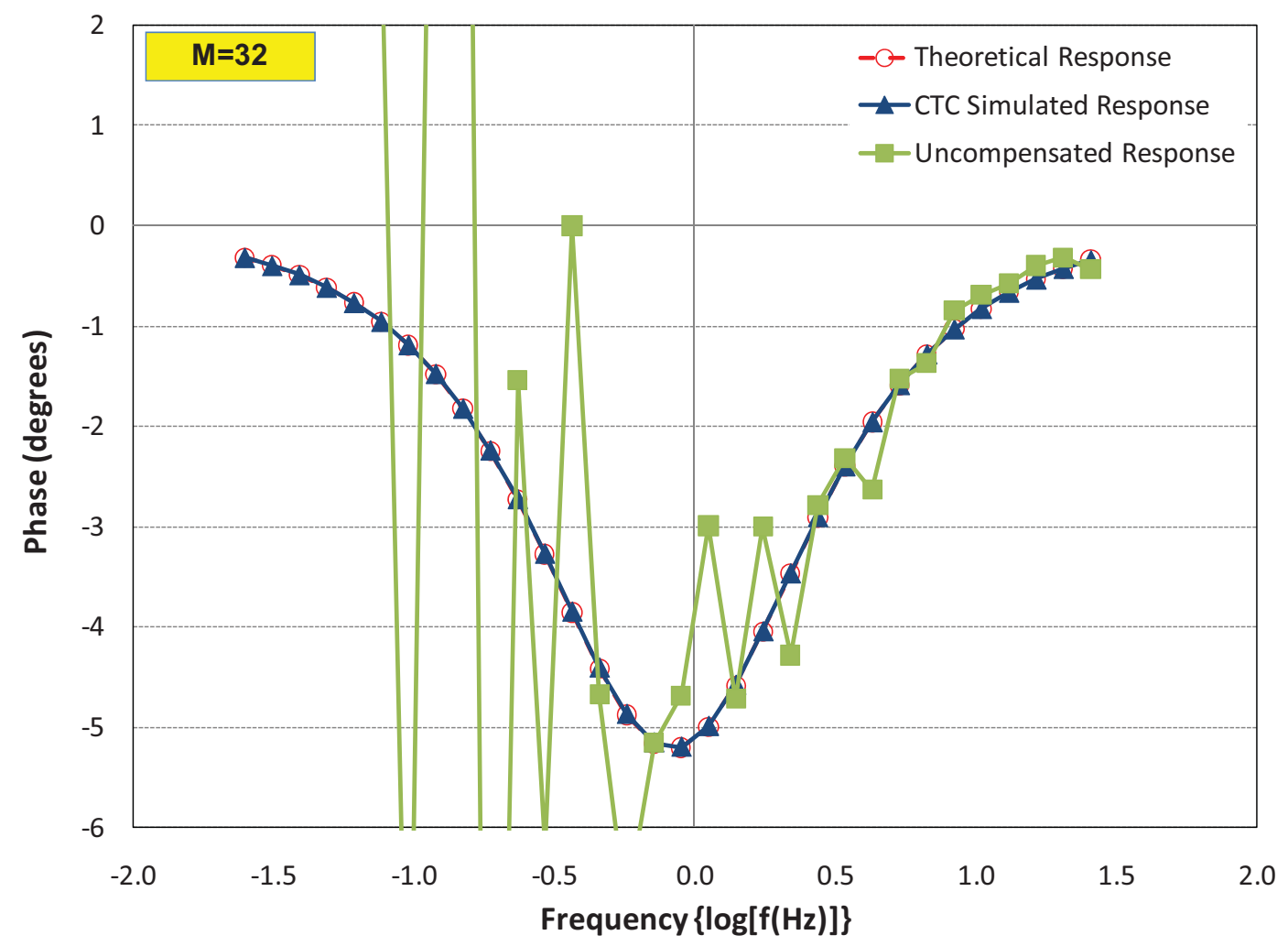

Figure 6b. Phase response between 25.6 and $0.025 \mathrm{~Hz}$ with 32 frequencies.

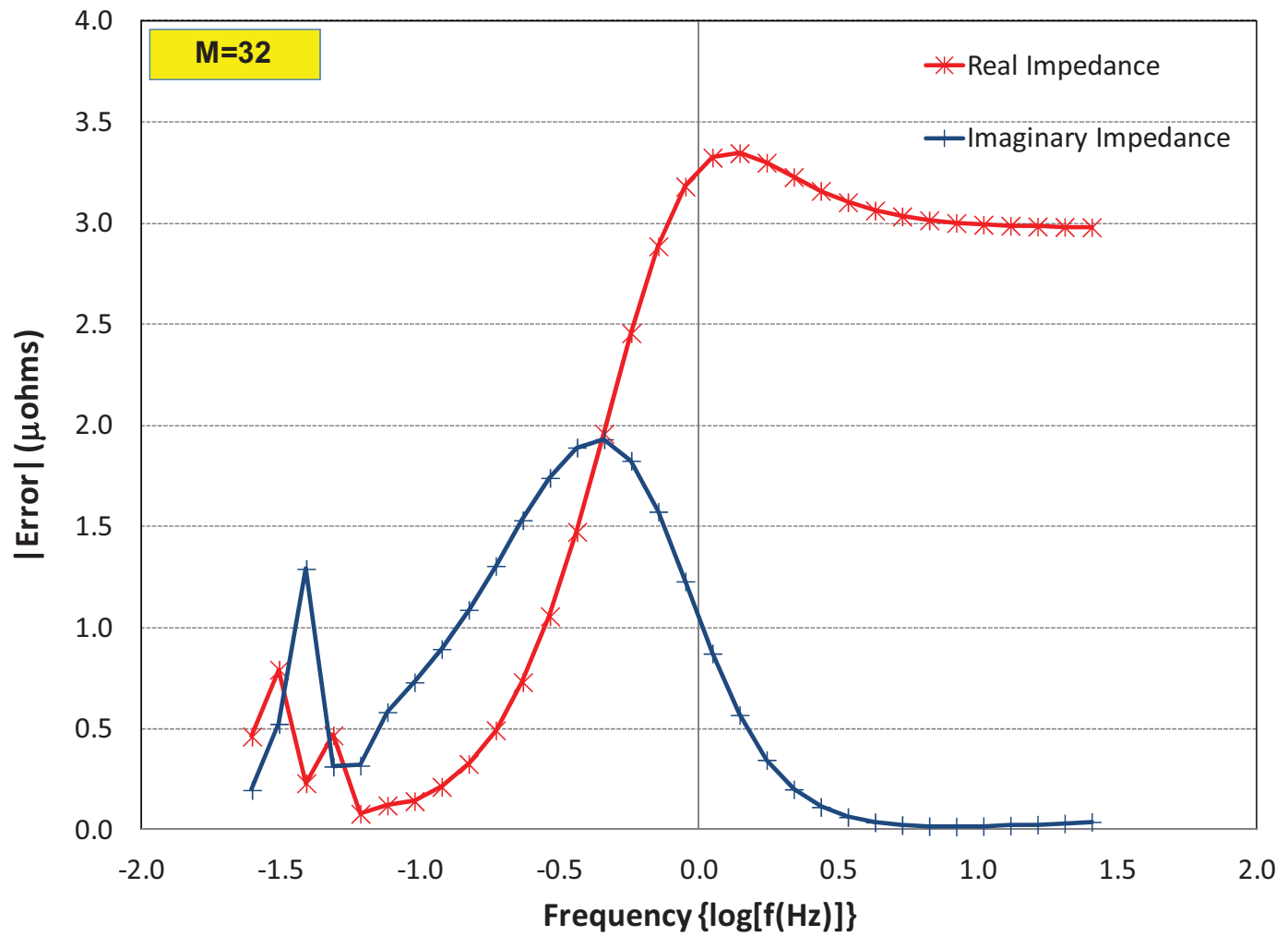

Figure 7. Error between theoretical and simulated results. 
Table 1. Maximum error between theoretical and simulated results between 25.6 and $0.025 \mathrm{~Hz}$.

\begin{tabular}{cccccccc}
\hline \hline M & 11 & 20 & 25 & 32 & 33 & 34 \\
\hline S & 2.00 & 1.44 & 1.33 & 1.25 & 1.24 & 1.23 \\
\hline \hline Magnitude Error & $3.28 \mu \Omega$ & $3.29 \mu \Omega$ & $3.29 \mu \Omega$ & $3.29 \mu \Omega$ & $15.78 \mu \Omega$ & $78.84 \mu \Omega$ \\
Phase Error & $0.008^{\circ}$ & $0.008^{\circ}$ & $0.008^{\circ}$ & $0.008^{\circ}$ & $0.081^{\circ}$ & $0.403^{\circ}$ \\
Real Error & $3.32 \mu \Omega$ & $3.35 \mu \Omega$ & $3.34 \mu \Omega$ & $3.35 \mu \Omega$ & $15.67 \mu \Omega$ & $78.54 \mu \Omega$ \\
Imaginary Error & $1.92 \mu \Omega$ & $1.93 \mu \Omega$ & $1.93 \mu \Omega$ & $1.93 \mu \Omega$ & $21.11 \mu \Omega$ & $105.38 \mu \Omega$ \\
\hline \hline
\end{tabular}

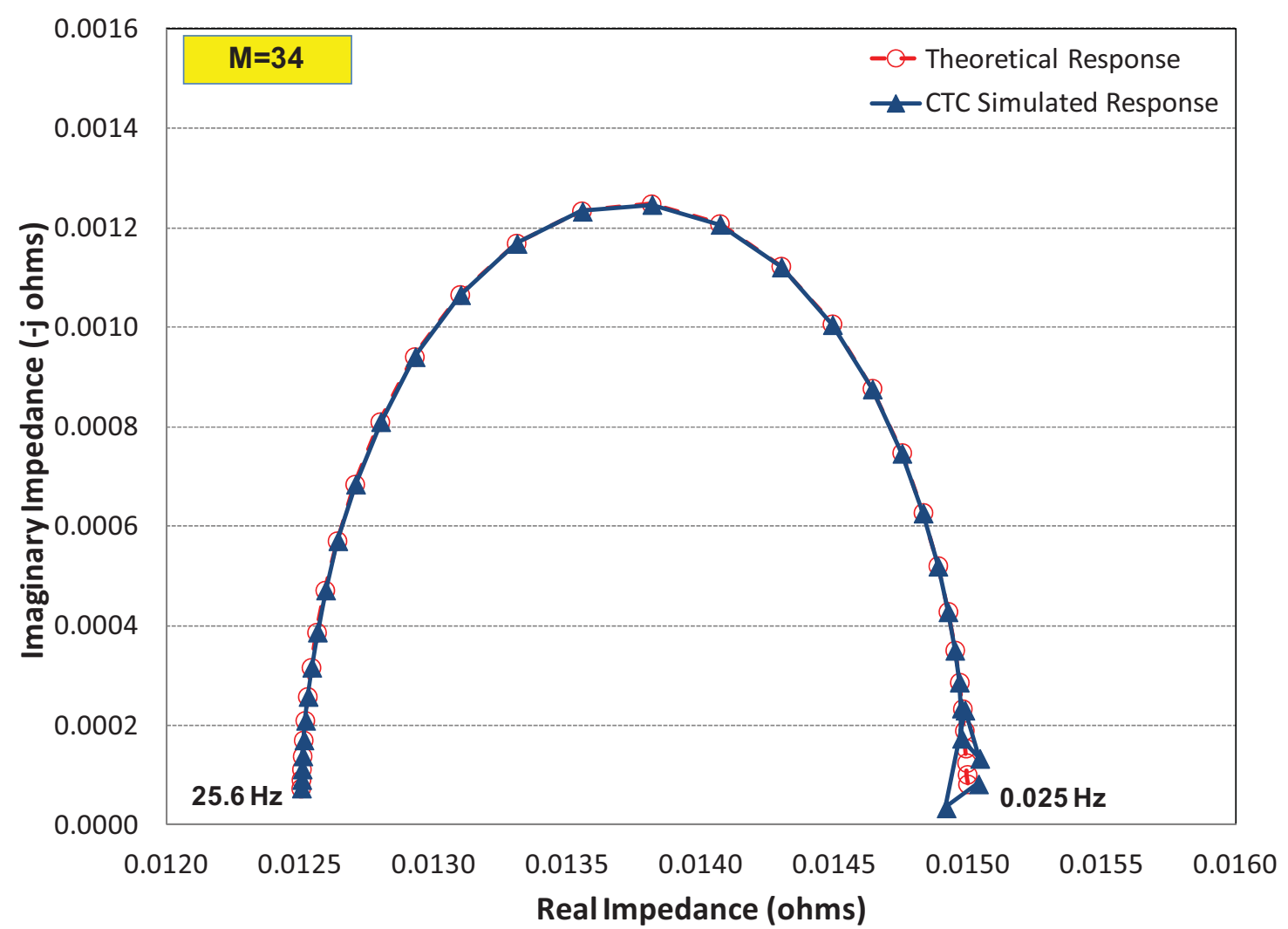

Figure 8. Nyquist curve between 25.6 and $0.025 \mathrm{~Hz}$ with 34 frequencies.

The high and low frequencies are harmonically related when 15 frequencies are used in the sum-of-sines excitation signal (i.e., $0.1 \mathrm{~Hz} * 2^{14}=1638.4 \mathrm{~Hz}$ ). Thus, there is no crosstalk interference and the error matrix, $C$, is a 30 by 30 identity matrix when assembled in the frequency domain. Figure 9 shows the resulting theoretical and simulated CTC impedance spectra for this frequency range. As before, the harmonic separation yields low-resolution data that inadequately describe the semicircle. A low frequency of $0.1 \mathrm{~Hz}$ does not sufficiently capture the right edge of the semicircle arc, but the edge could be inferred through extrapolation (e.g., with a linear extrapolation between the simulated impedance at 0.1 and $0.2 \mathrm{~Hz}$, the edge of the semicircle arc is estimated to be $15.1 \mathrm{~m} \Omega$ ). Increasing the resolution of the spectra should also increase the accuracy of this extrapolation.
The first frequency range used in the simulation indicated that the minimum step factor between frequencies for a logarithmic distribution should be 1.25 . For this frequency range (1638.4 to $0.1 \mathrm{~Hz}$ ), a step factor of 1.25 results in 45 frequencies of interest embedded within the sum-of-sines excitation signal. Figures 10 and 11 show the resulting theoretical and simulated impedance spectra with the Nyquist and Bode plots, respectively. As expected, the semicircle arc is much better defined with increased resolution in the spectra. Using a linear extrapolation to find the right edge of the semicircle arc based on the last two low-frequency points in the simulation yields an estimate of $15.04 \mathrm{~m} \Omega$, which is much closer to the actual value of $15.0 \mathrm{~m} \Omega$. The uncompensated responses, also shown in these figures, still converge towards the theoretical response as the detected frequency of interest gets bigger, resulting in more periods within the overall excitation signal. 
Table 2 shows the maximum error calculated from Equation (11) in the magnitude, phase, real, and imaginary components of the impedance for increasing frequencies. The maximum error in the real impedance is below $34 \mu \Omega$ $(0.026 \%$ of the corresponding theoretical real impedance) and the imaginary component is below $31 \mu \Omega$ at its peak $(0.620 \%$ of the corresponding theoretical imaginary impedance) for $M=45$. The error does not change significantly when one more frequency is added to the sum- of-sines excitation signal (i.e., $M=46$ and $S=1.24$ ) but shows significant increase when $M=47$. These data also indicate that the minimum step factor between frequencies should be around 1.25 or 1.24 given the TCC model. Figure 12 shows the compensated Nyquist curve when 47 frequencies are included in the sum-of-sines excitation signal. The error in the simulated response is clearly evident in the lower frequency region when the step factor is made too small.

Table 2. Maximum error between theoretical and simulated results between 1638.4 and $0.1 \mathrm{~Hz}$.

\begin{tabular}{ccccccc}
\hline \hline $\mathrm{M}$ & 15 & 30 & 40 & 45 & 46 & 47 \\
\hline $\mathrm{S}$ & 2.00 & 1.40 & 1.28 & 1.25 & 1.24 & 1.23 \\
\hline \hline Magnitude Error & $3.28 \mu \Omega$ & $3.29 \mu \Omega$ & $3.29 \mu \Omega$ & $3.29 \mu \Omega$ & $3.29 \mu \Omega$ & $83.88 \mu \Omega$ \\
Phase Error & $0.027^{\circ}$ & $0.027^{\circ}$ & $0.027^{\circ}$ & $0.027^{\circ}$ & $0.027^{\circ}$ & $0.404^{\circ}$ \\
Real Error & $3.32 \mu \Omega$ & $3.34 \mu \Omega$ & $3.34 \mu \Omega$ & $3.35 \mu \Omega$ & $3.35 \mu \Omega$ & $81.96 \mu \Omega$ \\
Imaginary Error & $1.92 \mu \Omega$ & $2.44 \mu \Omega$ & $2.87 \mu \Omega$ & $3.05 \mu \Omega$ & $3.07 \mu \Omega$ & $104.94 \mu \Omega$ \\
\hline \hline
\end{tabular}

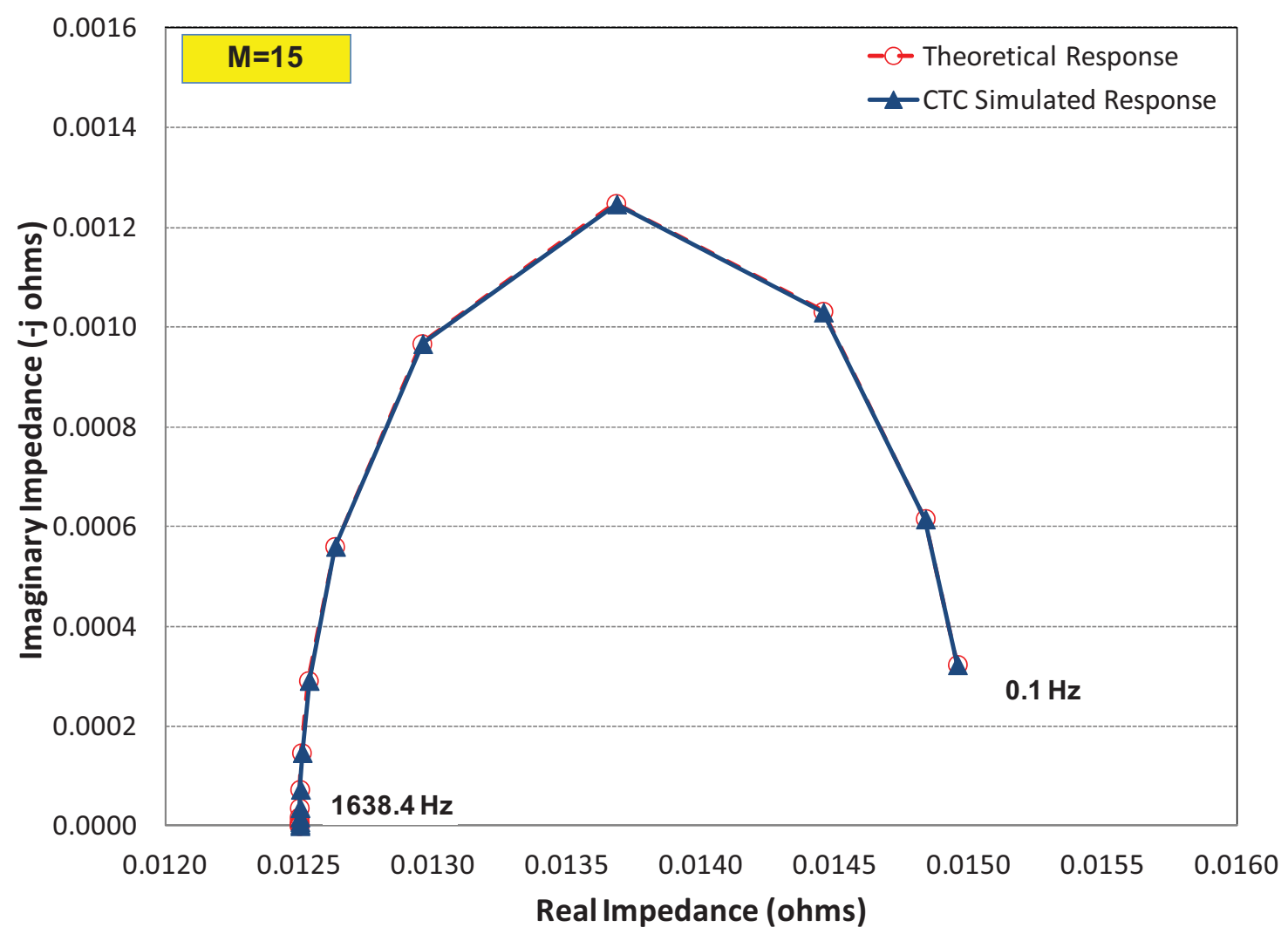

Figure 9. Nyquist curve between 1638.4 and $0.1 \mathrm{~Hz}$ using a harmonic frequency spread. 


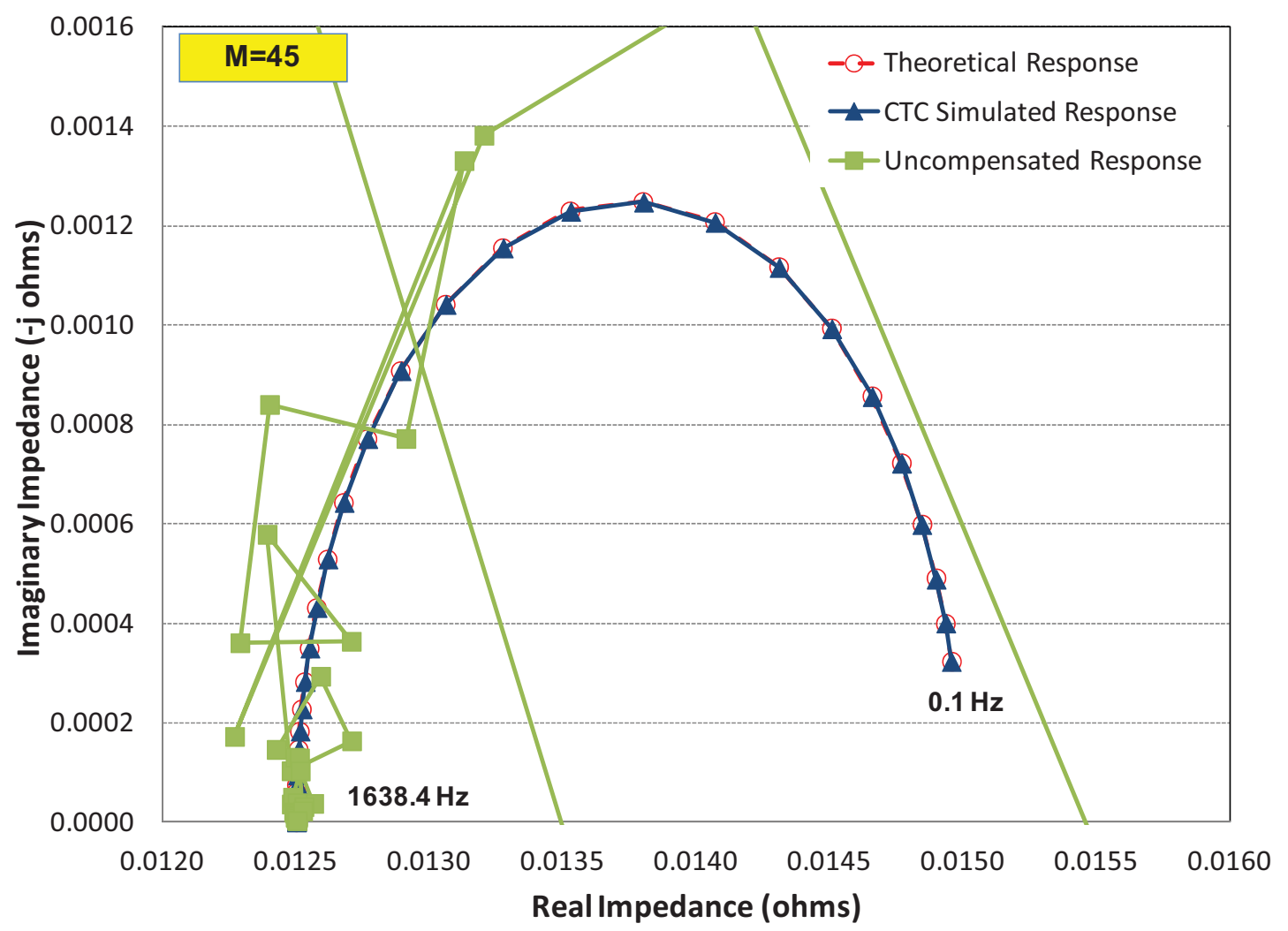

Figure 10. Nyquist curve between 1638.4 and $0.1 \mathrm{~Hz}$ with 45 frequencies.

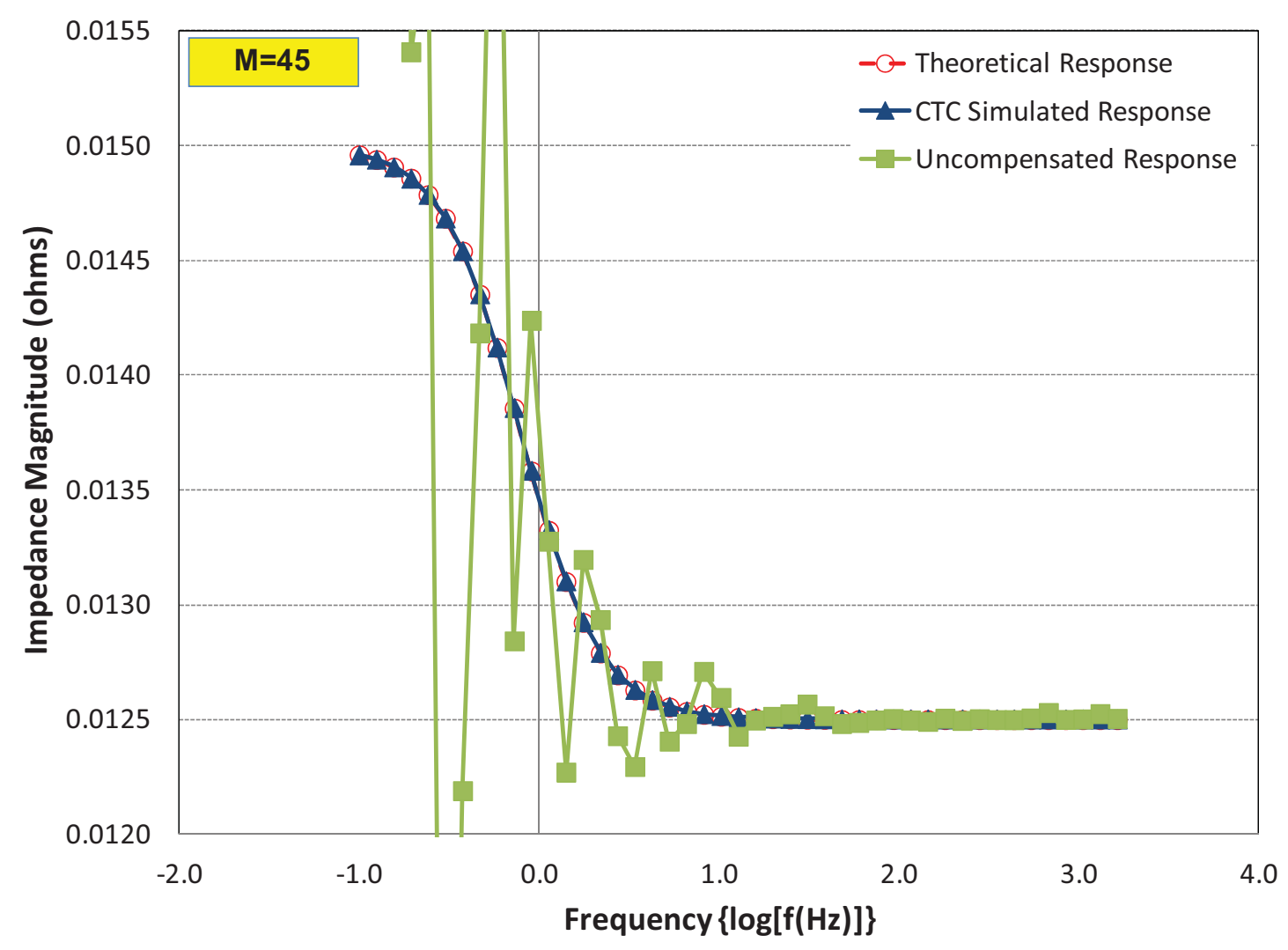

Figure 11a. Magnitude response between 1638.4 and $0.1 \mathrm{~Hz}$ with 45 frequencies. 


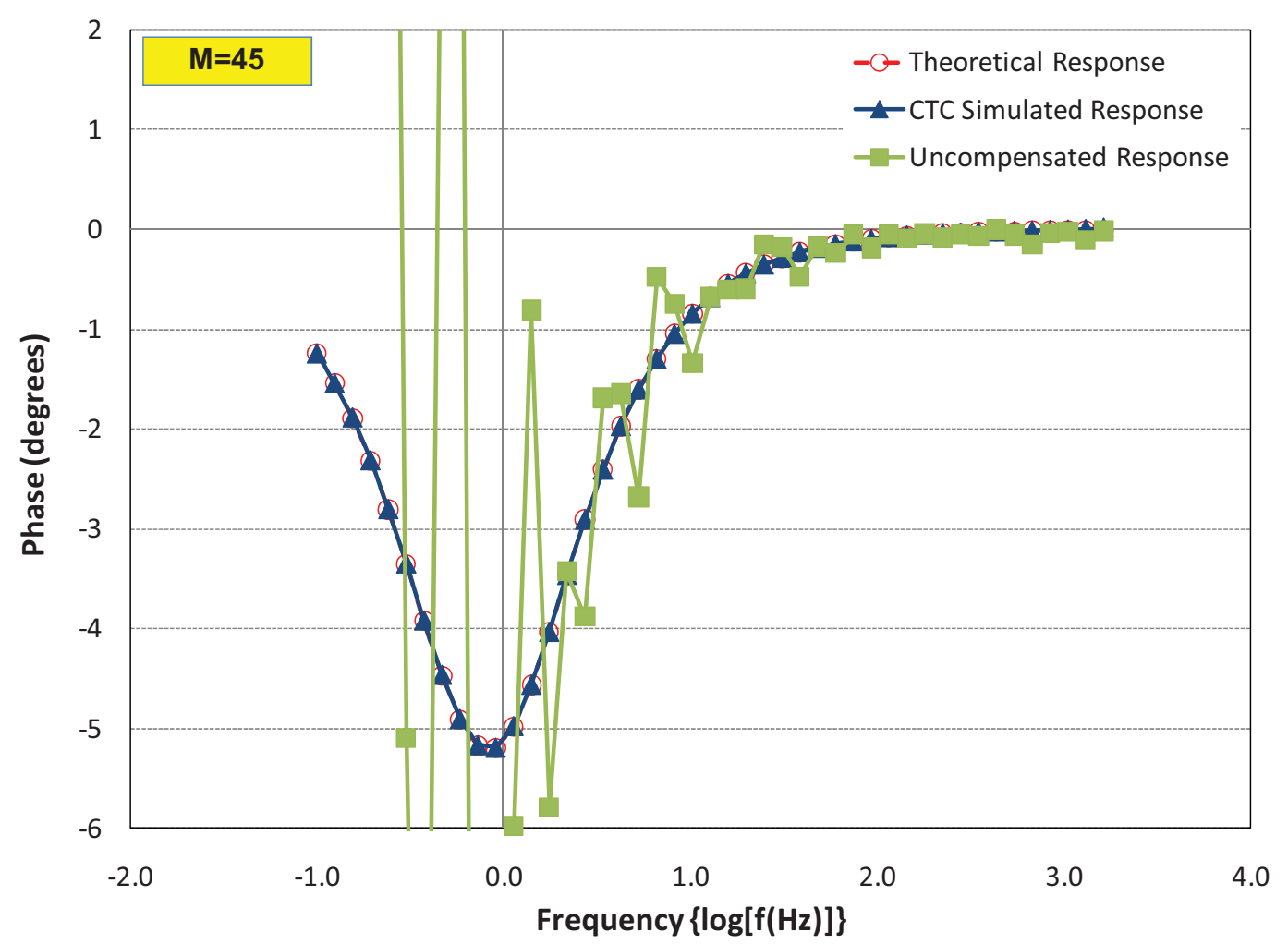

Figure 11b. Phase response between 1638.4 and $0.1 \mathrm{~Hz}$ with 45 frequencies.

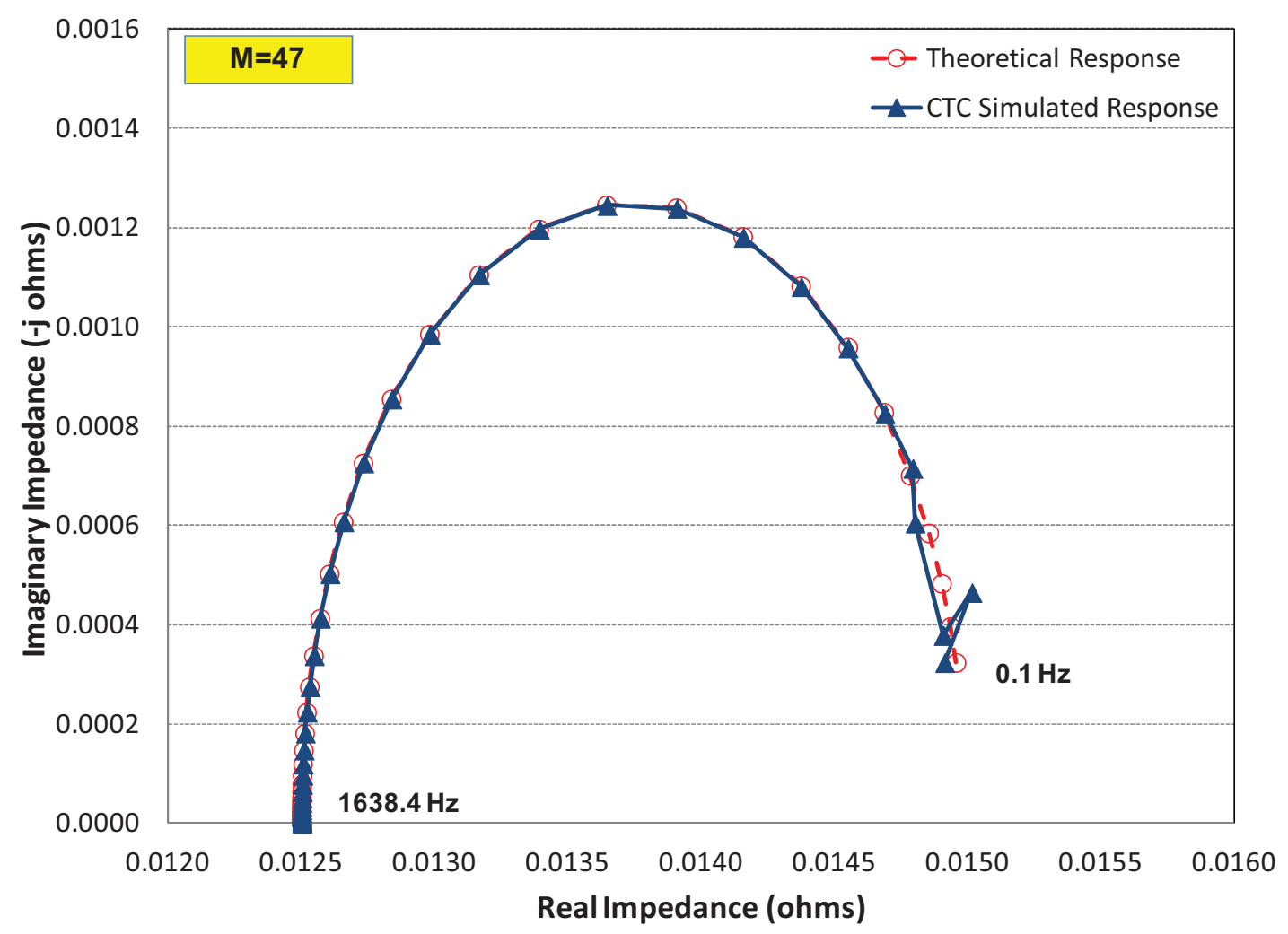

Figure 12. Nyquist curve between 1638.4 and $0.1 \mathrm{~Hz}$ with 47 frequencies. 


\section{SumMARY AND CONCLUSIONS}

Crosstalk Compensation is a novel technique that enables high-resolution impedance spectra to be acquired rapidly. The excitation signal is a sum of sinusoids that can be separated in various ways (e.g., logarithmically, linearly, etc.). Since the characteristics of the sum-of-sines excitation signal are known, the crosstalk interference between sinusoids can be pre-determined and assigned to an error matrix. Once the response signal of the energy storage device is captured and synchronously detected, it can be compensated by the inverse of the pre-calculated error matrix to rapidly identify the in-phase and quadrature components of the impedance (free of crosstalk interference) at each frequency of interest. The purpose of the simulation studies discussed herein was to assess the capability of Crosstalk Compensation to rapidly acquire high-resolution impedance spectra within one period of the lowest frequency using a logarithmic spread. It was shown from the simulated results that sum-of-sines signals separated by harmonics do not have crosstalk interference (i.e., the error matrix is the identity matrix), but the resulting spectra are sparse and do not adequately describe the charge transfer resistance semicircle arc. Increasing the number of frequencies within the sum-of-sines signal yields a much better description of the semicircle once the captured response signal is compensated by the error matrix. However, overly high resolution of the impedance spectra can cause errors in measurements as well. The two frequency ranges used in these simulations indicated that the minimum step factor between frequencies should be about 1.25 to avoid corrupting the spectra, especially at the lower frequencies where fewer periods are included within the overall excitation signal. Therefore, Crosstalk Compensation is a rapid measurement approach that provides high-resolution results that are comparable to the theoretical response of an equivalent circuit model. The next step in validating the Crosstalk Compensation technique is to acquire measurements on cell chemistries and evaluate the response compared to standardized AC impedance sweeps.

\section{NOMENCLATURE}

AC alternating current

CSD Compensated Synchronous Detection

CTC Crosstalk Compensation

FST Fast Summation Transformation

$\mathrm{SOH}$ state-of-health

SOC state-of-charge

TCC test cell circuit

\section{ACKNOWLEDGEMENTS}

This work was prepared as an account of work sponsored by an agency of the United States Government under US DOE Contract DE-AC07-05ID14517. Funding for this work was provided by the U.S. DOE Office of Vehicle Technologies. The U.S. Government retains and the publisher, by accepting the article for publication, acknowledges that the U.S. Government retains a nonexclusive, paid-up, irrevocable, worldwide license to publish or reproduce the published form of this manuscript, or allow others to do so, for U.S. Government purposes.

This information was prepared as an account of work sponsored by an agency of the U.S. Government. Neither the U.S. Government nor any agency thereof, nor any of their employees, makes any warranty, express or implied, or assumes any legal liability or responsibility for the accuracy, completeness, or usefulness of any information, apparatus, product, or process disclosed, or represents that its use would not infringe privately owned rights. References herein to any specific commercial product, process, or service by trade name, trademark, manufacturer, or otherwise, does not necessarily constitute or imply its endorsement, recommendation, or favoring by the U.S. Government or any agency thereof. Views and opinions of the authors expressed herein do not necessarily state or reflect those of the U.S. Government or any agency thereof.

\section{REFERENCES}

[1] M. Sternad, M. Cifrain, D. Watzenig, G. Brasseur, and M. Winter. Condition monitoring of lithium-ion batteries for electric and hybrid electric vehicles. 2009, Elektrotech. Informationstechnik, Vol. 126 (5), pp. 186-193.

[2] W.D. Kurle, S.B. Johnson, R.W. Nordness, S.L. Firman, D.M. Gustavson, P.Y. Choi. Smart Battery with Maintenance and Testing Functions. U.S. Patent 6,072,299 June 6, 2000.

[3] C.R. Gould, C.M. Bingham, D.A. Stone, and P. Bentley. New Battery Model and State-of-Health Determination through Subspace Parameter Estimation and State-Observer Techniques. 2009, IEEE Trans. Veh. Technol., Vol. 58 (8), pp. 3905-3916.

[4] T. Okoshi, K. Yamada, T. Hirasawa and A. Emori. Battery condition monitoring (BCM) technologies about lead-acid batteries. 2006, J. Power Sources, Vol. 158, pp. 874-878.

[5] V. Pop, H.J. Bergveld, P.H.L. Notten, and P.P.L. Regtien. State-of-the-art of battery state-of-charge determination. 2005, Meas. Sci. Tech., Vol. 16 (12), pp. R93-R110.

[6] Tinnemeyer, J. Fuzzy Logic Method and Apparatus for Battery State of Health Determination. U.S. Patent 7,072,871 B1 July 4, 2006.

[7] A. Banaei, A. Khoobroo, B. Fahimi. Online detection of terminal voltage in $\mathrm{Li}$-ion batteries via battery impulse response. 2009. Proceedings from the 5th IEEE Vehicle Power and Propulsion Conference. pp. 194-198. 
[8] B. Hariprakash, S.K. Martha, A. Jaikumar, A.K. Shukla. On-line monitoring of lead-acid batteries by galvanostatic non-destructive technique. 2004, J. Power Sources, Vol. 137 (1), pp. 128-133.

[9] J.P. Christophersen, D.F. Glenn, C.G. Motloch, R.B. Wright, C.D. Ho, V.S. Battaglia. Electrochemical Impedance Spectroscopy Testing on the Advanced Technology Development Program Lithium-Ion Cells. 2002, IEEE Trans. Veh. Technol., Vol. 56 (3), pp. 1851-1855.

[10] J.P. Christophersen, I. Bloom, E.V. Thomas, K.L. Gering, G.L. Henriksen, V.S. Battaglia, and D. Howell. Advanced Technology Development Program for Lithium-Ion Batteries: Gen 2 Performance Evaluation Final Report, INL/EXT-05-00913. 2006.

[11] J.P. Christophersen, C.D. Ho, C.G. Motloch, D. Howell, and H. Hess. Effects of Reference Performance Testing during Aging Using Commercial Lithium-Ion Cells. 2006, J. Electrochem Soc., Vol. 153, pp. A1406-A1416.

[12] Kozlowski, J.D. A Novel Online Measurement Technique for AC Impedance of Batteries and Other Electrochemical Systems. 2001. Proceedings from the 16th Annual Battery Conference. pp. 257-262.

[13] Tinnemeyer, J. Multiple Model Systems and Methods for Testing Electrochemical Impedance Systems. U.S. Patent 6,778,913 B2 August 17, 2004.

[14] P. Singh, R. Vinjamuri, X.Q. Wang, D. Reisner. Fuzzy logic modeling of EIS measurements on lithium-ion batteries. 2006, Electrochim. Acta, Vol. 51 (8-9), pp. 1673-1679.

[15] J. Yoo, S. Park. An Electrochemical Impedance Measurement Technique Employing Fourier Transform. 2000, Anal. Chem., Vol. 72, pp. 2035-2041.

[16] C.O. Yoon, Y. Barsukov, J.H. Kim. Method of and Apparatus for Measuring Battery Capacity by Impedance Spectrum Analysis. 6,208,147 B1 March 27, 2001.

[17] J.L. Morrison, W.H. Morrison. Method of Detecting System Function by Measuring Frequency Response. U.S. Patent 7,395,163 B1 July 1, 2008.

[18] J.L. Morrison, W.H. Morrison. Real Time Estimation of Battery Impedance. 2006. Proceedings from the IEEE Aerospace Conference.

[19] J.L. Morrison, J.P. Christophersen, and W.H. Morrison. Fast Summation Transformation: Method of Detecting System Function by Measuring Frequency Response Continuation. Montana Tech of the University of Montana. 2008. U.S. Patent Application.
[20] John L. Morrison, B. Smyth, J. Wold, D.K. Butherus, W.H. Morrison, J.P. Christophersen, C.G. Motloch. Fast Summation Transformation for Battery Impedance Identification. 2009. Proceedings from the IEEE Aerospace Conference.

[21] Linden, D.L., Reddy, T.B., [ed.]. Handbook of Batteries. 3. New York : McGraw Hill, 2002.

\section{BIOGRAPHIES}

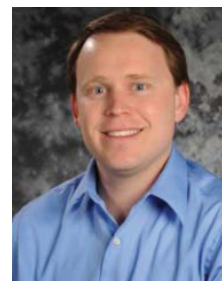

Jon P. Christophersen received a B.S. and M.S. in electrical engineering from the University of Idaho (Moscow, ID) in 1999 and 2005, respectively, and a Ph.D. from Montana State University (Bozeman, MT) in electrical engineering in May 2011. He has been a research engineer with the Energy Storage and Transportation Systems Department at the Idaho National Laboratory since February 2000. He has lead responsibility for all high-power-cell testing, analyses, and reporting under the U.S. Department of Energy's Applied Battery Research and Technology Life Verification Testing Programs, as well as various battery and ultracapacitor manufacturer deliverables as part of the U.S. Advanced Battery Consortium (USABC) Program. His research interests include battery life prognostics and state-of-health estimation. He received an R\&D 100 Award in 2011 for the Impedance Measurement Box, which offers innovative breakthroughs on rapid impedance measurement techniques for onboard monitoring of energy storage devices. He has authored or co-authored over 15 peer-reviewed journal publications and has one patent and several patents pending.

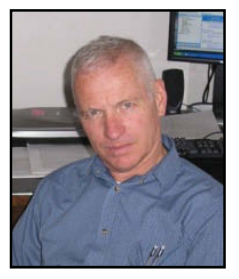

John L. Morrison has been teaching Electrical Engineering courses and advising graduate students for Montana Tech of the University of Montana since 2001. He had taken early retirement from the Idaho National Environmental and Engineering Laboratory (INEEL) in the early summer of 2001. He holds a Ph. D. in Electrical Engineering from the University of Idaho (1992) and an M.S. and B.S. in Electrical Engineering from the University of Connecticut (1967, 1968). He previously taught Electrical Engineering courses for the University of Idaho branch in Idaho Falls. He served as a Visiting Professor at Idaho State University in Pocatello, Idaho, for a 3-year appointment (1997-2000). He received an $R \& D 100$ Award in 2011 for the Impedance Measurement Box, which offers innovative breakthroughs on rapid impedance measurement techniques for onboard monitoring of energy storage devices. 


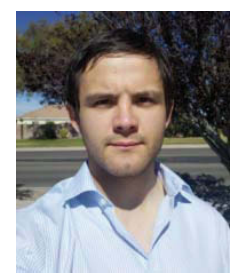

David M. Rose graduated from Montana Tech of the University of Montana in May 2009 with a B.S. in Electrical Engineering and in May 2011 with a M.S. in Electrical Engineering. While he was an undergraduate, he worked as in intern for the Idaho National Laboratory (INL) with an emphasis on the rapid impedance measurement techniques. He developed a deep interest in signal processing and significantly contributed to the development of the Crosstalk Compensation technique. As an INL intern, his Master's thesis work consisted of analytically and physically validating the Crosstalk Compensation technique in both the frequency and time domain. After graduation in May 2011, he went to work as an Energy Storage Test Engineer at the Sandia National Laboratories.

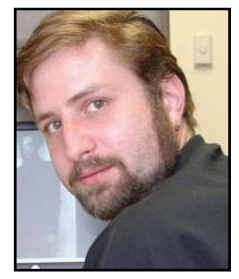

William H. Morrison is a Systems Engineer at QSI. Mr. Morrison's current project involves data normalization for the Pratt \& Whitney F119 engine. Past projects include fault diagnostics and prognostics for the F/A-18 C/D aileron servoactuator, including development of a complete nonlinear Simulink model of an electrohydraulic servovalve, development of a data driven prognostic solution for the Advanced Airborne Sensor as part of the Airborne Laser Theater Missile Defense Program, and prognostic monitoring of the nozzle and actuation hardware for the F135 engine for the Joint Strike Fighter. Mr. Morrison's interests involve intelligent prognostic and diagnostic solutions and algorithms and finding new and innovative ways to apply them. Mr. Morrison received his B.S. in Electrical Engineering (2003) from the University of Connecticut. He is currently taking graduate level courses towards his Masters degree. He received an R\&D 100 Award in 2011 for the Impedance Measurement Box, which offers innovative breakthroughs on rapid impedance measurement techniques for onboard monitoring of energy storage devices.

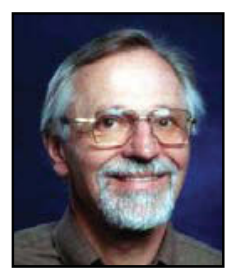

Chester G. Motloch received a B.S. in Physics from UCLA, a M.S. in Physics from Oakland University, and a Ph.D in Engineering and Applied Science from Idaho State University. He retired from the U.S. Department of Energy's Idaho National Laboratory in 2005 where he was the group leader in the Advanced Energy and Systems Transportation Department in charge of advanced energy storage performance testing, analyses, and procedures development. He is now president of Motloch Consulting, Inc., and specializes in laboratory and vehicle advanced battery performance testing and prognostics. He received an R\&D 100 Award in 2011 for the Impedance Measurement Box, which offers innovative breakthroughs on rapid impedance measurement techniques for onboard monitoring of energy storage devices. 